\title{
Correlation of 5-HTT, BDNF and NPSR1 gene polymorphisms with anxiety and depression in asthmatic patients
}

\author{
YUAN YANG ${ }^{1}$, MINGZHE ZHAO $^{2}$, YUQUN ZHANG $^{3}$, XINHUA SHEN $^{4}$ and YONGGUI YUAN ${ }^{3}$ \\ ${ }^{1}$ Department of Respiratory Medicine, Zhongda Hospital Affiliated to Southeast University; \\ ${ }^{2}$ Medical College of Southeast University; ${ }^{3}$ Department of Psychosomatics and Psychiatry, \\ Zhongda Hospital Affiliated to Southeast University, Nanjing, Jiangsu 210009; \\ ${ }^{4}$ Department of Neurosis and Psychosomatic Diseases, Huzhou 3rd Hospital, \\ Huzhou, Zhejiang 313000, P.R. China
}

Received July 13, 2015; Accepted April 15, 2016

DOI: 10.3892/ijmm.2016.2581

\begin{abstract}
Asthmatic patients are known to have a higher risk of anxiety and depression. In the present study, we aimed to explore the association of serotonin transporter (5-HTT), brain-derived neurotrophic factor (BDNF) and neuropeptide $\mathrm{S}$ receptor 1 (NPSR1) gene polymorphisms with anxiety and depression in asthmatic patients. This was a cross-sectional study conducted on 143 asthmatic patients and 175 healthy volunteers. Of the asthmatic patients, 49 suffered from anxiety and 12 exhibited signs of depression. Patients with a lower level of education were more prone to depression. Both anxiety and depression were associated with poor asthma control as evaluated by the Asthma Control Test (ACT) score. The association of single nucleotide polymorphisms of BDNF, NPSR1 and 5-HTT with anxiety and depression in asthamtic patients was evaluated. The distribution of 5-HTT gene polymorphisms in the healthy group, the group with asthma but without anxiety, and the group with asthma and anxiety had significant differences. Females with asthma and anxiety were more prone to BDNF polymorphism. Also, BDNF gene distribution exhibited significant differences among those in the healthy group, the group with asthma but no depression, and the group with asthma and depression; however, NPSR1 gene distribution did not vary greatly between the groups. The anxiety score was significantly affected by the interaction between 5-HTT (LL, $\mathrm{S}^{+}$) and BDNF $\left(\mathrm{A}^{+}, \mathrm{GG}\right)(\mathrm{H}=5.99, \mathrm{P}=0.015)$. The depression score was significantly affected by the interaction between BDNF $\left(\mathrm{A}^{+}, \mathrm{GG}\right)$ and NPSR1 $\left(\mathrm{AA}, \mathrm{T}^{+}\right)$. We noted that both anxiety and depression led
\end{abstract}

Correspondence to: Dr Yuan Yang, Department of Respiratory Medicine, Zhongda Hospital Affiliated to Southeast University, 87 Dingjiaqiao, Nanjing, Jiangsu 210009, P.R. China

E-mail: yyuan_nj@163.com

Key words: asthmatic patients, anxiety, depression, serotonin transporter, brain-derived neurotrophic factor, neuropeptide $\mathrm{S}$ receptor 1, gene polymorphisms to poor asthma control. The interaction between 5-HTT (LL) and $\mathrm{BDNF}\left(\mathrm{A}^{+}\right)$increased the risk of anxiety, and the interaction between BDNF $\left(\mathrm{A}^{+}, \mathrm{GG}\right)$ and NPSR1 (AA, $\left.\mathrm{T}^{+}\right)$increased the risk of depression in asthmatic patients.

\section{Introduction}

Bronchial asthma is a chronic inflammatory disease of the respiratory tract which is characterized by airway hyper-responsiveness and reversible airflow restriction. Currently, standardized treatment and self-management by patients have significantly reduced the incidence of acute asthmatic attacks. However, asthma remains a disease which does not yet have a complete cure (1). Psychological problems are common in asthmatic patients, even in patients who have well-controlled asthma. Valença et al (2) reported that $43.5 \%$ of patients with asthma had at least one type of psychiatric disorder. Anxiety and depression are the two most common disorders encountered in asthmatic patients, and tend to correlate with asthma control $(3,4)$. A recent study reported that anxiety and depression occurred in 33.3 and $47.7 \%$ asthmatic patients, respectively (5).

Asthmatic patients are at a higher risk of psychiatric morbidity, with anxiety and depression being the two most common disorders in these patients (3,4,6-12). Asthma significantly affects psychological and social wellbeing due to the impact it has on routine activities, sleep and the daily life of patients (3,4,6-12). Conversely, psychological factors may be a risk factor for the exacerbation of this disorder. Another theory regarding the link between asthma and psychological factors describes asthma as a classic psychosomatic disorder caused by specific psychological conflicts (13).

The serotonin transporter (5-HTT) is known to be associated with depression and emotional stress (14). The 5'-flanking promoter region of the 5-HTT gene has a biallelic insertion/deletion (5-HTTLPR) (15). Furthermore, it has been reported that the 5-HTTLPR genotype is linked with severe depression (15); the polymorphisms within this region are associated with improved responses to treatment with selective serotonin reuptake inhibitors (16). Brain-derived neurotrophic factor (BDNF) is a growth factor which belongs to the neurotrophin family 
and is highly expressed in the hippocampus and amygdala of the brain (17). It regulates the pathophysiology of mood disorders, including major depressive disorder (MDD) and bipolar disorder (BD), as well as learning and memory $(17,18)$. Patients with anxiety and BD are known to have decreased levels of BDNF $(17,18)$. Previous studies have also implicated BDNF in the pathogenesis of asthma (19-21). Furthermore, the BDNF gene polymorphism has been reported to be associated with allergic asthma and allergic rhinitis (22).

Neuropeptide S receptor 1 (NPSR1) gene has been suggested to be a candidate gene which is associated with increased susceptibility to asthma and other atopic disorders in different populations (23). The signaling system of NPSR1 and its ligand neuropeptide S (NPS) have been implicated in various pathophysiological pathways, including regulation of the immunologic phenotype and various neurobiological phenomena such as wakefulness, arousal, anxiety, learning and memory (23).

To the best of our knowledge, the association of NPSR1, BDNF and 5-HTT gene polymorphisms with anxiety or depression in asthmatic patients has not been previously examined. Hence, this study was undertaken in order to correlate anxiety and depression with the clinical characteristics of asthmatic patients, and to explore their association with 5-HTT, BDNF and NPSR1 gene polymorphisms.

\section{Subjects and methods}

Subjects. This study was approved by the Medical Ethics Committee for Clinical Research, Zhongda Hospital Affiliated to Southeast University (Nanjing, China). Written informed consent was obtained from all subjects. The inclusion criteria were as follows: patients were of Han Chinese ethnicity aged $>18$ years, who had been diagnosed with bronchial asthma as per the diagnostic criteria established by the Respiratory Diseases Branch of the Chinese Medical Association (24), without mental disorders according to the diagnostic standard of the Diagnostic and Statistical Manual of Mental Disorders, 4th Edition (DSM2IV), and had completed at least primary education. Subjects with chronic diseases (diabetes, hypertension, coronary heart disease, chronic obstructive pulmonary disease and genetic diseases), pregnant or lactating women or individuals with a history of drug abuse were excluded from the study. The healthy controls were volunteers from Zhongda Hospital, which included hospital staff, doctors and medical students.

Assessment of asthma control, anxiety and depression. All patients completed questionnaires using the Hamilton Anxiety Rating Scale (HAMA), the Hamilton Depression Rating Scale (HAMD) and the Asthma Control Test (ACT) score (11). Asthma without anxiety was defined as a HAMA anxiety score $\leq 14$ points; asthma with anxiety was defined as a HAMA anxiety score $>14$ points; asthma without depression was defined as a HAMD depression score $\leq 7$ points; and asthma with depression was defined as a HAMD depression score $>7$ points.

Genomic DNA preparation. Blood for genomic studies was collected from all asthma patients and healthy controls in an ethylenediaminetetraacetic acid (EDTA) vial. The genomic
DNA was extracted from $3 \mathrm{ml}$ of EDTA-anticoagulated whole blood using a Blood Genomic DNA Extraction kit (cat. no. DP318; Tiangen Biotech (Beijing) Co., Ltd., Beijing, China) according to the manufacturer's instructions. The quality and quantity of genomic DNA extracted was examined with spectrophotometry (ND-1000; NanoDrop products, Thermo Fisher Scientific, Wilmington, DE, USA). All extracted DNA had an OD260/280 between 1.7 and 1.9. The purified DNA samples were stored at $-80^{\circ} \mathrm{C}$ until further testing.

Polymerase chain reaction (PCR) amplification and genotyping. Genotyping of BDNF, NPSR1 and 5-HTT was performed using the PCR-restriction fragment length polymorphism (PCR-RFLP) and direct sequencing (GenScript Corp., Nanjing, China). For detecting single nucleotide polymorphisms (SNPs), 5-HTT (5-HTTLPR), BDNF (rs6265) and NPSR1 (rs324981) genes were amplified using PCR. The sequences of all primers and the conditions of PCR-RFLP analysis for the three polymorphisms (5-HTTLPR for 5-HTT, rs324981 for NPSR1 and rs6265 for BDNF) are summarized in Table I. Each SNP site for DNA sequencing was randomly selected from $10 \%$ of the samples. The sequencing was performed using the dideoxynucleotide termination method.

Statistical analysis. All statistical analyses were conducted using SPSS statistical analysis software (version 19.0; IBM SPSS, Chicago, IL, USA). Hardy-Weinberg equilibrium (HWE) was evaluated for each SNP in all groups. The Satterthwaite test was used to compare the differences in age between groups with and without anxiety or depression. The Chi-square test was used to compare the differences in genotypic distribution among groups. The interactive effects of different genotypes on the anxiety/depression scores were analyzed using the Scheirer-Ray-Hare test. A P-value $<0.05$ was considered to indicate a statistically significant difference.

\section{Results}

Baseline characteristics of subjects. The baseline characteristics of the subjects are summarized in Table II. A total of 143 (male 63, female 80) asthmatic patients were examined in this study. There were 49 patients with anxiety and 94 without anxiety. There were 12 patients with depression and 131 without depression. There were 20 males and 29 females with anxiety, and 7 males and 5 females with depression. A total of 175 (male 51, female 124) healthy controls, (mean age, $39.11 \pm 14.98$ years) were included in this study. The mean age of the asthmatic patients was $50.22 \pm 12.95$ years. The mean age of the patients with and without anxiety was $52.76 \pm 10.13$ and $48.9 \pm 14.08$ years, respectively, with no significant difference in age between the two groups $(\mathrm{t}=-1.88, \mathrm{P}=0.063)$. Similarly, no significant difference was observed between the mean ages of patients with and without depression [54.08 \pm 8.21 and $49.87 \pm 13.27$ years, respectively $(\mathrm{t}=-1.08, \mathrm{P}=0.283)]$. These results suggest that the occurrence of both anxiety and depression in asthmatic patients is not associated with age. Both age and gender were significantly different in the group with asthma and the group with asthma and anxiety (age, $\mathrm{F}=25.74$, $\mathrm{P}<0.0001$; gender, $\left.\chi^{2}=7.95, \mathrm{P}=0.019\right)$, when compared with healthy controls. 
Table I. Characterization of PCR reaction conditions for the analyzed single nucleotide polymorphisms.

Target

Primer sequence $\left(5^{\prime} \rightarrow 3^{\prime}\right)$
$\operatorname{Tm}\left({ }^{\circ} \mathrm{C}\right)$

Restriction enzyme
Allele sizes (bp)

\section{5-HTT}

BDNF (rs6265)

NPSR1 (rs324981)
F: GGCGTTGCCGCTCTGAATGC

R: GAGGGACTGAGCTGGACAACC

F: ACTCTGGAGAGCGTGAATGG

R: ACTACTGAGCATCACCCTGGA

F: GCTTTGCATTTCCTCAGTGG

R: ATTTGTGGCTCGTTTGTGTTTTCT
59

60

Eco72I

AseI

Ase

G: 99,72

T: 471

A: 277,194

5-HTT, serotonin transporter; Tm, annealing temperature $\left({ }^{\circ} \mathrm{C}\right)$; BDNF, brain-derived neurotrophic factor (BDNF); NPSR1, neuropeptide S receptor $1 ; \mathrm{F}$, forward; $\mathrm{R}$, reverse.

Table II. Baseline characteristics of study subjects.

\begin{tabular}{|c|c|c|c|c|c|c|c|c|}
\hline Variable & Healthy & Asthma & $\begin{array}{l}\text { Asthma } \\
\text { without } \\
\text { anxiety }\end{array}$ & $\begin{array}{l}\text { Asthma } \\
\text { with } \\
\text { anxiety }\end{array}$ & Statistics & $\begin{array}{c}\text { Asthma } \\
\text { without } \\
\text { depression }\end{array}$ & $\begin{array}{l}\text { Asthma } \\
\text { with } \\
\text { depression }\end{array}$ & Statistics \\
\hline Total & 175 & 143 & 94 & 49 & & 131 & 12 & \\
\hline Age (years) & $39.11 \pm 14.98$ & $50.22 \pm 12.95$ & $48.9 \pm 14.08$ & $52.76 \pm 10.13$ & $\begin{array}{l}\mathrm{t}=-1.88 \\
\mathrm{P}=0.063\end{array}$ & $49.87 \pm 13.27$ & $54.08 \pm 8.21$ & $\begin{array}{l}\mathrm{t}=-1.08, \\
\mathrm{P}=0.283 \\
\mathrm{~F}=25.74, \\
\mathrm{P}<0.0001\end{array}$ \\
\hline \multicolumn{9}{|l|}{ Gender } \\
\hline Male & 51 & 63 & 43 & 20 & & 56 & 7 & $\chi^{2}=7.95$, \\
\hline Female & 124 & 80 & 51 & 29 & & 75 & 5 & $\mathrm{P}=0.019$ \\
\hline \multicolumn{9}{|l|}{ Education } \\
\hline 1 & & & $4(4.35)$ & $2(4.08)$ & $\chi^{2}=0.29$, & $5(3.88)$ & $1(8.33)$ & $\chi^{2}=5.70$ \\
\hline 2 & & & $22(23.91)$ & $14(28.57)$ & $P=0.59$ & $29(22.48)$ & $7(58.33)$ & $\mathrm{P}=0.017$ \\
\hline 3 & & & $34(36.96)$ & $18(36.73)$ & & $50(38.76)$ & $2(16.67)$ & \\
\hline 4 & & & $32(4.78)$ & $15(30.61)$ & & $45(34.88)$ & $2(16.67)$ & \\
\hline ACT score & N/A & $18.49 \pm 4.51$ & $19.77 \pm 4$ & $16.04 \pm 4.47$ & $\mathrm{P}<0.05$ & $18.9 \pm 4.37$ & $14 \pm 3.67$ & $\begin{array}{l}\mathrm{t}=0.76, \\
\mathrm{P}=0.0002\end{array}$ \\
\hline
\end{tabular}

ACT, Asthma Control Test. Education was graded as follows: 1, primary school; 2, junior high school; 3, senior high school and technical secondary school; 4, college and university.

In the present study, patients who were less educated were more likely to suffer from depression $\left(\chi^{2}=5.70, \mathrm{P}=0.017\right)$ rather than anxiety $\left(\chi^{2}=0.29, \mathrm{P}=0.59\right)$. Our results suggest a negative correlation between depression and education levels, possibly due to the educated patients having a better understanding of asthma and other diseases. Upon evaluation of the ACT score, we noted that asthma patients with anxiety and depression had lower scores as compared to those without any psychiatric illness (anxiety, 16.04 $\pm 4.47 ; \mathrm{P}<0.05$ and depression, $14 \pm 3.67 ; \mathrm{P}=0.0002$ ). These findings suggest a negative correlation of the ACT score with both anxiety and depression in asthmatic patients.

Association of 5-HTT gene polymorphisms with anxiety and depression in asthmatic patients. To examine the association of 5-HTT gene polymorphisms with anxiety and depression in asthmatic patients, we analyzed the frequency of 5-HTT genotypes in the healthy control group, the groups with asthma but without anxiety/depression, and the groups with asthma and anxiety/depression (Table III and Fig. 1). In addition, 5-HTT gene polymorphisms were not detected in 6 healthy subjects. Therefore, there were data from 169 healthy subjects shown in Table III.

The majority of healthy individuals had the SS (59.17\%) genotype. However, in the group with asthma but without anxiety, the majority had the LS (56.67\%) genotype, followed by SS (42.22\%) and LL (11.11\%) genotypes. In the group with asthma and anxiety, the LS and SS genotypes accounted for 44.68 and $48.94 \%$, respectively, whereas LL accounted for only $6.38 \%$. None of the females had the LL genotype in this group. There were significant differences in the distribution of 5-HTT genotypes in the group with asthma but without anxiety, and the group with asthma and anxiety, when compared with the healthy controls $\left(\chi^{2}=10.18, P=0.038\right)$. Furthermore, there were 
Table III. Genotype distributions and allele frequencies of 5-HTT polymorphisms for asthmatic patients vs. control group.

\begin{tabular}{lrrrrr}
\hline & \multicolumn{5}{c}{ Genotype } \\
\cline { 2 - 4 } Subject & \multicolumn{1}{c}{ LL } & LS & SS & Total & Statistics \\
\hline Healthy & $6(3.55)$ & $63(37.28)$ & $100(59.17)$ & 169 & \\
Male & $3(6.12)$ & $17(34.69)$ & $29(59.18)$ & 49 & \\
Female & $3(2.50)$ & $46(38.33)$ & $71(59.17)$ & 120 & \\
Asthma without anxiety & $10(11.11)$ & $42(56.67)$ & $38(42.22)$ & 90 & \\
Male & $4(9.76)$ & $20(48.78)$ & $17(41.46)$ & 41 & \\
Female & $6(12.24)$ & $22(44.90)$ & $21(42.86)$ & 49 & \\
Asthma with anxiety & $3(6.38)$ & $21(44.68)$ & $23(48.94)$ & 47 & $\chi^{2}=10.18, \mathrm{P}=0.038$ \\
Male & $3(15.79)$ & $7(36.84)$ & $9(47.37)$ & 19 & $\chi^{2}=4.02, \mathrm{P}=0.43$ \\
Female & $0(0.00)$ & $14(50.00)$ & $14(50.00)$ & 28 & $\chi^{2}=10.97, \mathrm{P}=0.027$ \\
Asthma without depression & $12(9.52)$ & $59(46.83)$ & $55(43.65)$ & 126 & \\
Male & $6(11.32)$ & $24(45.28)$ & $23(43.40)$ & 53 & \\
Female & $6(8.22)$ & $35(47.95)$ & $32(43.84)$ & 73 & \\
Asthma with depression & $1(9.09)$ & $4(36.36)$ & $6(54.55)$ & 11 & $\chi^{2}=9.34, \mathrm{P}=0.053$ \\
Male & $1(14.29)$ & $3(42.86)$ & $3(42.86)$ & 7 & $\chi^{2}=3.04, \mathrm{P}=0.55$ \\
Female & $0(0.00)$ & $1(25.00)$ & $3(75.00)$ & 4 & $\chi^{2}=7.09, \mathrm{P}=0.13$ \\
\hline
\end{tabular}

5-HTT, serotonin transporter.
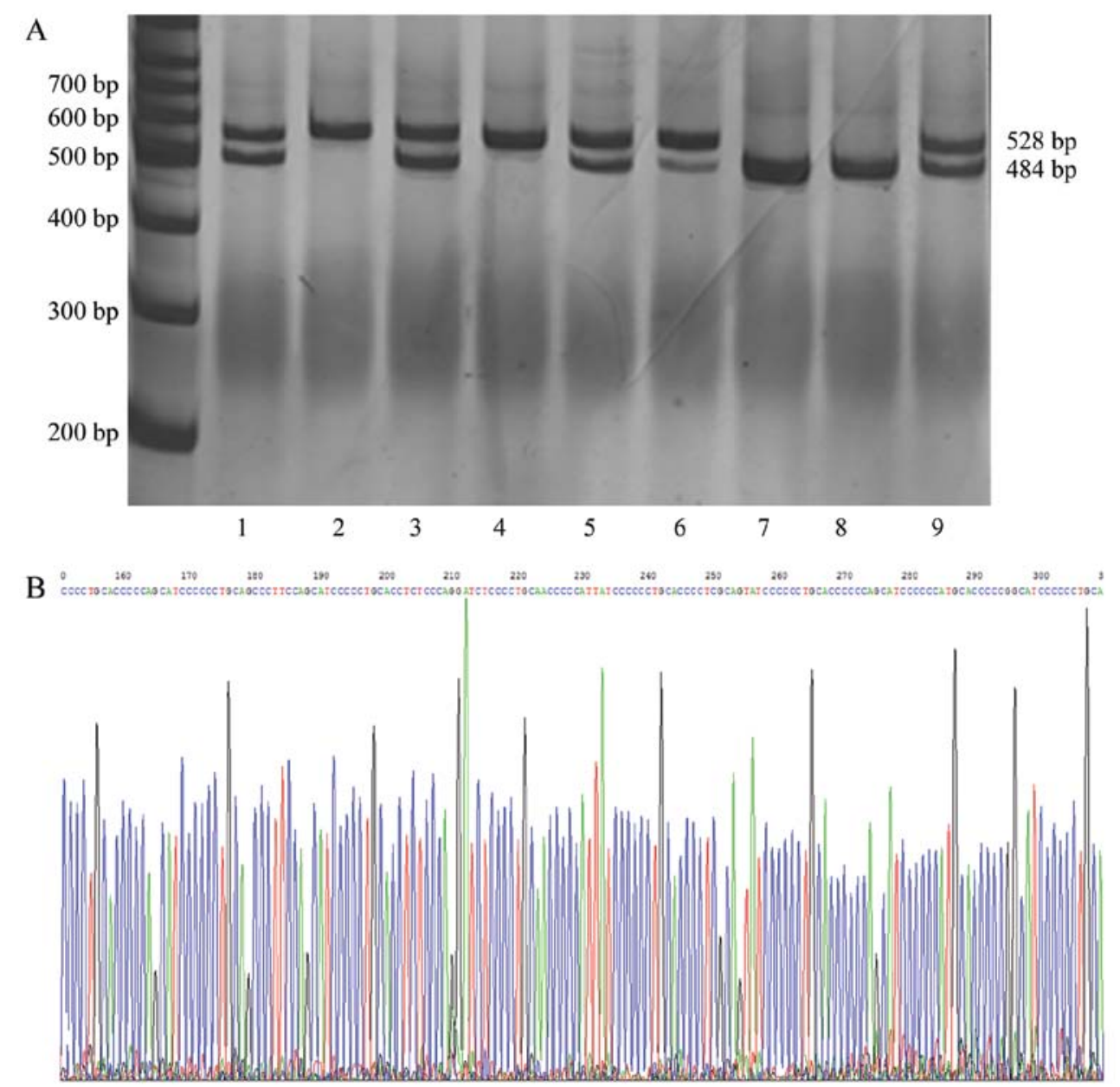

Figure 1. Genotyping single nucleotide polymorphism (SNP) (5-HTTLPR) in the serotonin transporter (5-HTT) gene. (A) PCR products were resolved in 3\% agarose gel. Lanes 1, 3, 5, 6, 2 and 4: LL, homozygous; lanes 7 and 8: SS, homozygous; and lane 9: SL, heterozygous. (B) Representative sequence of 5-HTTLPR. 
Table IV. Genotype distribution and allele frequencies of BDNF polymorphisms in asthmatic patients vs. controls.

\begin{tabular}{|c|c|c|c|c|c|}
\hline \multirow[b]{2}{*}{ Subject } & \multicolumn{3}{|c|}{ Genotype } & \multirow[b]{2}{*}{ Total } & \multirow[b]{2}{*}{ Statistics } \\
\hline & AA & $\mathrm{AG}$ & GG & & \\
\hline Healthy & $69(40.35)$ & $90(52.63)$ & $12(7.02)$ & 171 & \\
\hline Male & $22(43.14)$ & $27(52.94)$ & $2(3.92)$ & 51 & \\
\hline Female & $47(39.17)$ & $63(52.50)$ & $10(8.33)$ & 120 & \\
\hline Asthma without anxiety & $37(40.66)$ & $30(32.97)$ & $24(26.37)$ & 91 & \\
\hline Male & $17(40.48)$ & $17(40.48)$ & $8(19.05)$ & 42 & \\
\hline Female & $20(40.82)$ & $13(26.53)$ & $16(32.65)$ & 49 & \\
\hline Asthma with anxiety & $20(44.44)$ & $14(31.11)$ & $11(24.44)$ & 45 & $\chi^{2}=24.72, P<0.0001$ \\
\hline Male & $9(47.37)$ & $5(26.32)$ & $5(26.32)$ & 19 & $\chi^{2}=9.34, \mathrm{P}=0.053$ \\
\hline Female & $11(42.31)$ & $9(34.62)$ & $6(23.08)$ & 26 & $\chi^{2}=19.35, P=0.0007$ \\
\hline Asthma without depression & $52(41.6)$ & $42(33.6)$ & $31(24.8)$ & 125 & \\
\hline Male & $22(40.74)$ & $21(38.89)$ & $11(20.37)$ & 54 & \\
\hline Female & $30(42.25)$ & $21(29.58)$ & $20(28.17)$ & 71 & \\
\hline Asthma with depression & $5(45.45)$ & $2(18.18)$ & $4(36.36)$ & 11 & $\chi^{2}=26.40, P<0.0001$ \\
\hline Male & $4(57.14)$ & $1(14.29)$ & $2(28.57)$ & 7 & $\chi^{2}=10.82, P=0.029$ \\
\hline Female & $1(25.00)$ & $1(25.00)$ & $2(50.00)$ & 4 & $\chi^{2}=18.92, P=0.0008$ \\
\hline
\end{tabular}

BDNF, brain-derived neurotrophic factor.

significant differences in the distribution of 5-HTT genotypes among female patients $\left(\chi^{2}=10.97, \mathrm{P}=0.027\right)$ with asthma and anxiety when compared with healthy females. However, similar results were not noted for males. These findings suggest an association between the 5-HTT gene polymorphisms and female asthmatic patients with anxiety.

In the group with asthma without depression, the LS and SS genotypes accounted for 46.83 and $43.65 \%$, respectively; LL accounted for only $9.52 \%$. In the group with asthma and depression, LS and SS accounted for 36.36 and $54.55 \%$, respectively, whereas LL accounted for only $9.09 \%$. It is important to note that none of the females had the LL genotype. The Chi-square test showed that 5-HTT gene distributions in the healthy group, and in asthma patients with or without depression group were similar $\left(\chi^{2}=9.34, \mathrm{P}=0.053\right)$. Also, there was no gender bias between the three groups. These findings suggest that there is no association between 5-HTT gene polymorphisms and asthmatic patients with depression.

Association of BDNF gene polymorphisms with anxiety and depression. The frequency of BDNF gene polymorphisms in the healthy controls, asthmatic patients without anxiety/depression, and groups with asthma and anxiety/depression was also examined (Table IV and Fig. 2). In addition, BDNF gene polymorphisms were not detected in 4 healthy subjects. Therefore, there were data from 171 healthy subjects shown in Table IV. We noted that $52.63 \%$ of healthy individuals had the AG genotype. In the group with asthma but not anxiety, the major genotype of BNDF was AA (40.66\%), followed by AG $(32.97 \%)$ and GG (26.37\%). In the group with asthma and anxiety, the major genotype of BNDF was AA (44.44\%), followed by AG (31.11\%) and GG (24.44\%). BDNF genotype distributions in the group with asthma but not anxiety, and the group with asthma and anxiety $\left(\chi^{2}=24.72, \mathrm{P}<0.0001\right)$ were significantly different when compared with the control group. Furthermore, there were significant differences in the distribution of the BNDF genotype among the female asthmatic patients with anxiety when compared with healthy females $\left(\chi^{2}=19.35, \mathrm{P}=0.0007\right)$. A corresponding association was not observed in male patients. These findings suggest an association between BDNF gene polymorphisms and female asthmatic patients with anxiety.

In the group of asthmatic patients without depression $\mathrm{AA}, \mathrm{AG}$ and GG genotypes of BNDF accounted for 41.6, 33.6 and $24.8 \%$, respectively. In the group with asthma and depression, AA, AG and GG genotypes accounted for 45.45, 18.18 and $36.36 \%$, respectively. In this group, AA, AG and GG genotypes were present in 57.14, 14.29 and $28.57 \%$ of males, respectively, and $25.00,25.00$ and $50.00 \%$ of females, respectively. There were significant differences in the distribution of BDNF genotypes in the asthmatic patients with and without depression $\left(\chi^{2}=26.40, \mathrm{P}<0.0001\right)$, when compared with the healthy controls. Further analysis revealed significant differences in the distribution of BNDF genotypes among both male $\left(\chi^{2}=10.82, \mathrm{P}=0.029\right)$ and female patients $\left(\chi^{2}=18.92, \mathrm{P}=0.0008\right)$ with asthma and depression, when compared with healthy males and females, respectively. These findings suggest an association between BDNF gene polymorphisms and asthmatic patients with depression regardless of gender.

Association of NPSRl gene polymorphisms with anxiety and depression. To examine the association between NPSR1 gene polymorphisms and both anxiety and depression in asthmatic patients, we analyzed the frequencies of NPSR 1 genotypes in the healthy control group, the groups with asthma but without anxiety/depression, and the groups with asthma and 
A
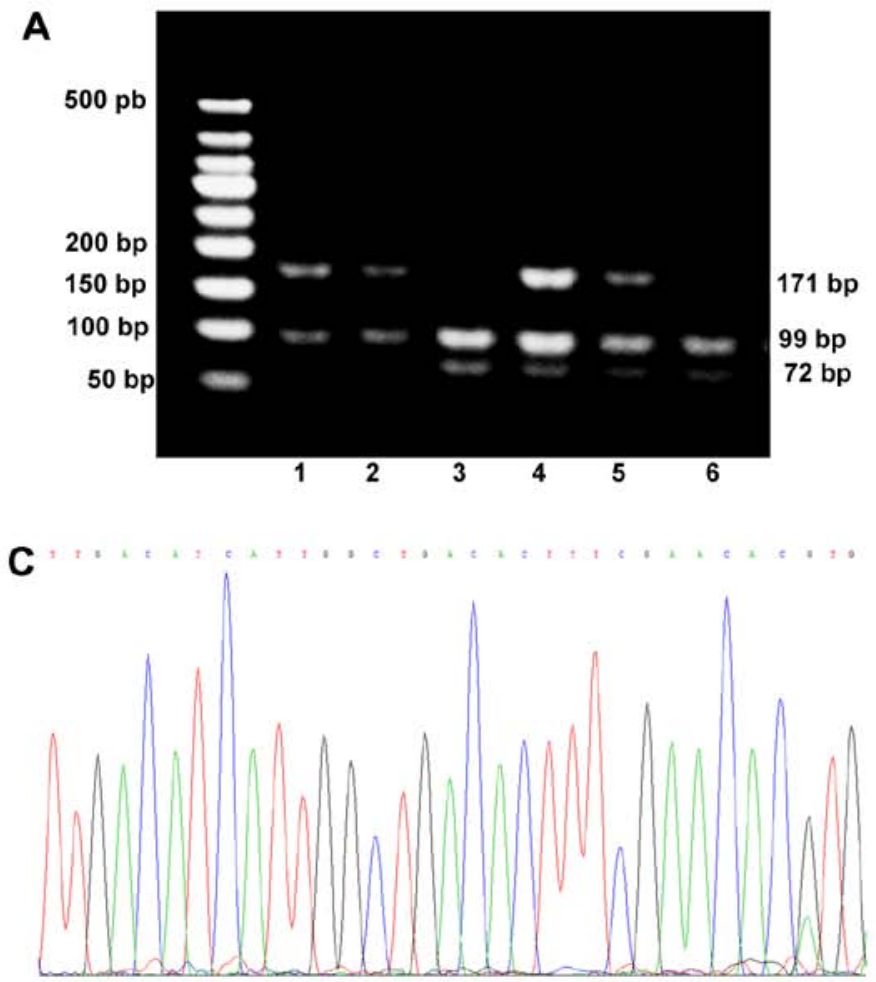

AG
B

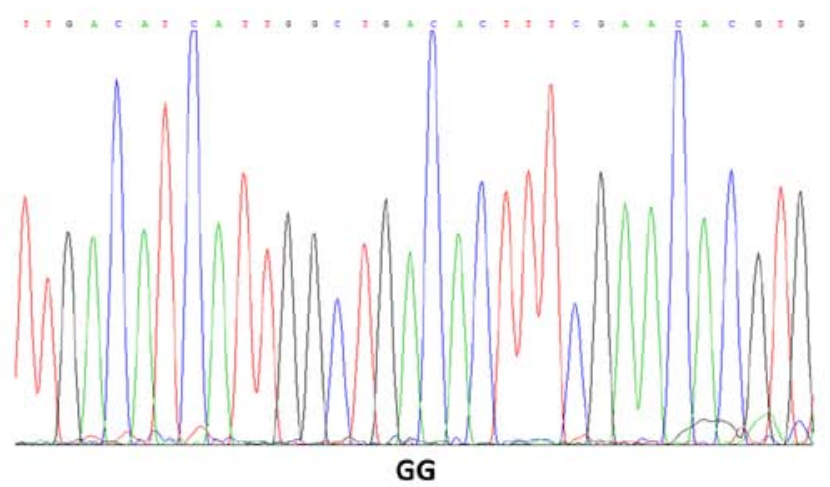

D

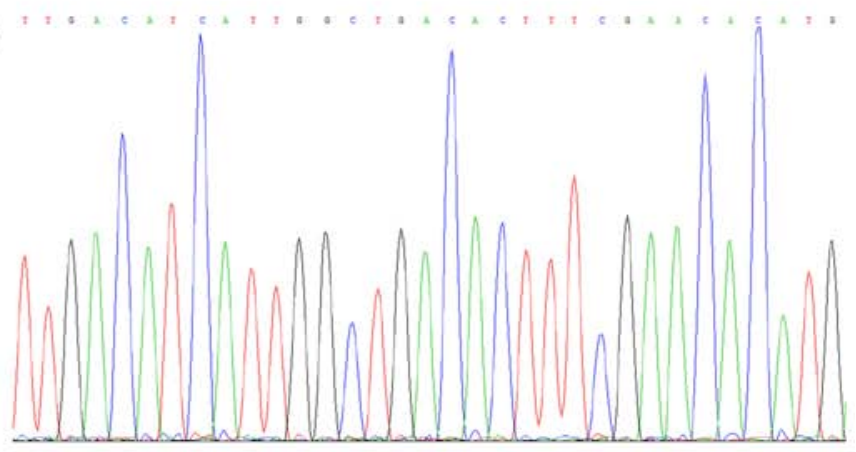

AA

Figure 2. Genotyping single nucleotide polymorphism (SNP) (rs6265) in the brain-derived neurotrophic factor (BDNF) gene. (A) PCR products were digested with Eco72I and resolved in 3\% agarose gel. Lanes 1 and 2: AA, homozygous; lanes 4 and 5: AG, heterozygous; and lanes 3 and 6: GG, homozygous. (B-D) Representative sequences of GG, AG and AA, respectively.

Table V. Genotype distribution and allele frequencies of NPSR1 polymorphisms in asthmatic patients vs. controls.

\begin{tabular}{|c|c|c|c|c|c|}
\hline \multirow[b]{2}{*}{ Subject } & \multicolumn{3}{|c|}{ Genotype } & \multirow[b]{2}{*}{ Total } & \multirow[b]{2}{*}{ Statistics } \\
\hline & TT & AT & AA & & \\
\hline Healthy & $59(34.50)$ & $79(46.20)$ & $33(19.30)$ & 171 & \\
\hline Male & $19(37.25)$ & $26(50.98)$ & $6(11.76)$ & 51 & \\
\hline Female & $40(33.33)$ & $53(44.17)$ & $27(22.50)$ & 120 & \\
\hline Asthma without anxiety & $26(28.57)$ & $49(53.85)$ & $16(17.58)$ & 91 & \\
\hline Male & $13(30.95)$ & $23(54.76)$ & $6(14.29)$ & 42 & \\
\hline Female & $13(26.53)$ & $26(53.06)$ & $10(20.41)$ & 49 & \\
\hline Asthma with anxiety & $16(34.78)$ & $20(43.48)$ & $10(21.74)$ & 46 & $\chi^{2}=1.94, P=0.75$ \\
\hline Male & $7(36.84)$ & $8(42.11)$ & $4(21.05)$ & 19 & $\chi^{2}=1.53, P=0.82$ \\
\hline Female & $9(33.33)$ & $12(44.44)$ & $6(22.22)$ & 27 & $\chi^{2}=1.23, P=0.87$ \\
\hline Asthma without depression & $40(31.75)$ & $62(49.21)$ & $24(19.05)$ & 126 & \\
\hline Male & $19(35.19)$ & $26(48.15)$ & $9(16.67)$ & 54 & \\
\hline Female & $21(29.17)$ & $36(50.00)$ & $15(20.83)$ & 72 & \\
\hline Asthma with depression & $2(18.18)$ & $7(63.64)$ & $2(18.18)$ & 11 & $\chi^{2}=1.72, P=0.79$ \\
\hline Male & $1(14.29)$ & $5(71.43)$ & $1(14.29)$ & 7 & $\chi^{2}=2.22, P=0.70$ \\
\hline Female & $1(25.00)$ & $2(50.00)$ & $1(25.00)$ & 4 & $\chi^{2}=0.72, P=0.95$ \\
\hline
\end{tabular}

NPSR1, neuropeptide S receptor 1.

anxiety/depression (Table V and Fig. 3). In addition, NPSR1 gene polymorphisms were not detected in 4 healthy subjects.
Therefore, there were data from 171 healthy subjects shown in Table V. 

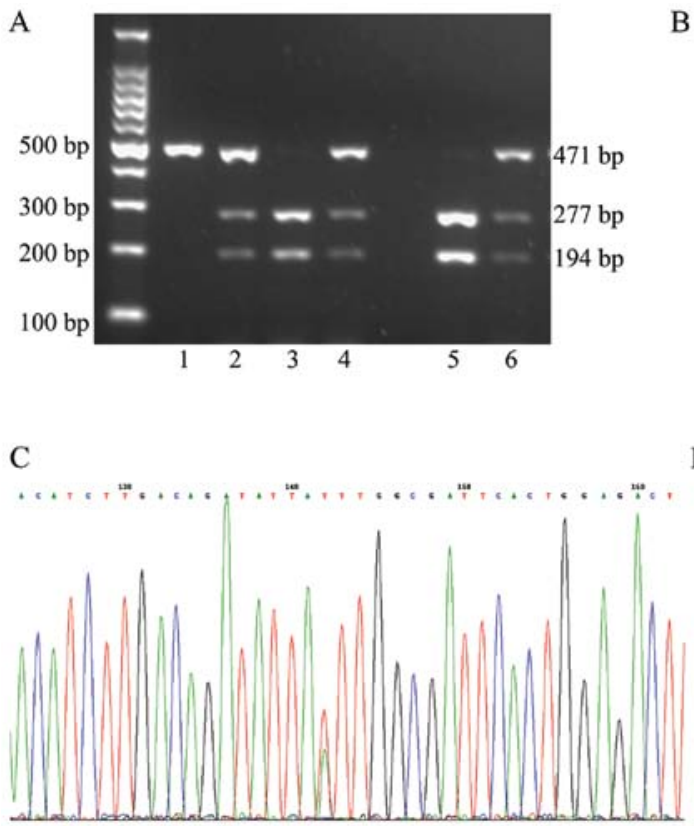

AT

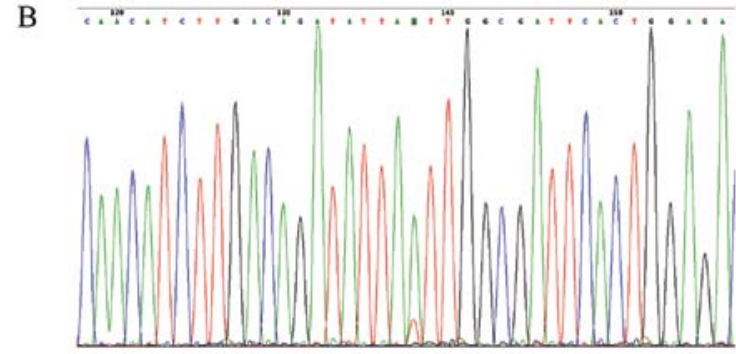

AA

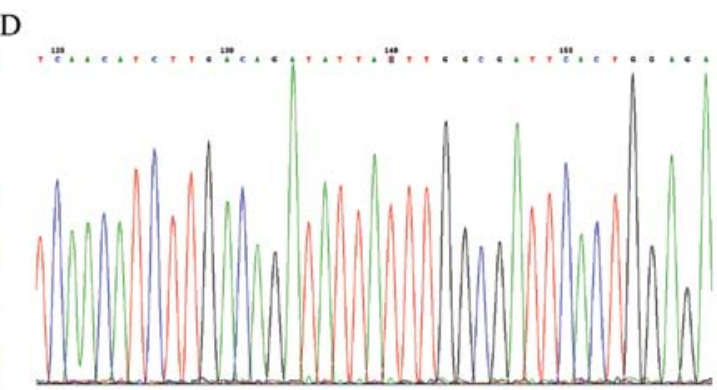

TT

Figure 3. Genotyping single nucleotide polymorphism (SNP) (rs324981) in the neuropeptide S receptor 1 (NPSR1) gene. (A) PCR products were digested with AseI and resolved in 3\% agarose gel. Lane 1: TT, homozygous; lanes 2, 4 and 6: AT, heterozygous; and lanes 3 and 5: AA, homozygous. (B-D) Representative sequence of $\mathrm{AA}, \mathrm{AT}$ and $\mathrm{TT}$, respectively.

Table VI. Genotype distributions of 5-HTT and BDNF and NPSR1 polymorphisms in asthmatic patients with and without anxiety or depression.

\begin{tabular}{|c|c|c|c|c|c|c|}
\hline & \multicolumn{2}{|c|}{ 5-HTT } & \multicolumn{2}{|c|}{ BDNF } & \multicolumn{2}{|c|}{ NPSR1 } \\
\hline & $\mathrm{S}^{+}$ & LL & $\mathrm{A}^{+}$ & GG & $\mathrm{T}^{+}$ & AA \\
\hline Asthma without anxiety & $84(89.36)$ & $10(10.64)$ & $70(74.47)$ & $24(25.53)$ & $78(82.98)$ & $16(17.02)$ \\
\hline Asthma with anxiety & $46(93.88)$ & $3(6.12)$ & $38(77.55)$ & $11(22.45)$ & $39(79.59)$ & $10(20.41)$ \\
\hline Asthma without depression & $119(90.84)$ & $12(9.16)$ & $100(76.34)$ & $31(23.66)$ & $107(81.68)$ & $24(18.32)$ \\
\hline Asthma with depression & $11(91.67)$ & $1(8.33)$ & $8(66.67)$ & $4(33.33)$ & $10(83.33)$ & $2(16.67)$ \\
\hline
\end{tabular}

5-HTT, serotonin-transporter; BDNF, brain-derived neurotrophic factor; NPSR1, neuropeptide S receptor 1.

In the healthy controls, NPSR1 genotypes AT, TT and AA accounted for $46.20,34.50$ and $19.30 \%$, respectively. Among the asthmatic patients, AT was the most common genotype that accounted for $53.85,43.48,49.21$ and $63.64 \%$, in asthma without anxiety, asthma with anxiety, asthma without depression, and asthma with depression, respectively; followed by TT (28.57, $34.78,31.75$ and $18.18 \%$, respectively); and AA $(17.58,21.74$, 19.05 and $18.18 \%$, respectively). NPSR 1 genotype distribution in the asthma without anxiety group, and the asthma with anxiety group $\left(\chi^{2}=1.94, \mathrm{P}=0.75\right)$ were not found to be significantly different when compared with healthy controls. Furthermore, there were no significant differences in genotype distribution among male $\left(\chi^{2}=1.53, \mathrm{P}=0.82\right)$ and female patients $\left(\chi^{2}=1.23, \mathrm{P}=0.87\right)$ in the asthma with anxiety group, when compared with healthy males and females, respectively. These findings suggest a lack of association between NPSR1 gene polymorphisms (both overall and gender related) and asthmatic patients with anxiety.
NPSR1 genotype distribution was not found to be significantly different in the asthma without depression group, and the asthma with depression group $\left(\chi^{2}=1.72, \mathrm{P}=0.79\right)$, when compared with healthy controls. Furthermore, there were no significant differences in genotype distribution among male $\left(\chi^{2}=2.22, \mathrm{P}=0.70\right)$ and female asthmatic patients $\left(\chi^{2}=0.72\right.$, $\mathrm{P}=0.95)$ with depression, when compared with healthy males and females, respectively. These findings also indicate a lack of association between NPSR1 gene polymorphisms (both overall and gender related) and depression in asthmatic patients.

Allele frequencies of 5-HTT, BDNF and NPSR1 in asthma patients with and without anxiety or depression. We analyzed the allele frequencies of 5-HTT, BDNF and NPSR1 in the asthmatic patients with and without anxiety or depression (Table VI). The majority of patients with asthma had the $\mathrm{S}^{+}$allele in the 5-HTT gene, $\mathrm{A}^{+}$in the BDNF gene and $\mathrm{T}^{+}$in the NPSR1 gene. The frequency of the $\mathrm{S}^{+}$allele in the 5-HTT 
Table VII. Interaction between 5-HTT and BDNF polymorphisms and its affect on the anxiety score of asthmatic patients.

\begin{tabular}{lccccc}
\hline & & & \multicolumn{2}{c}{ Anxiety score } & \\
\cline { 4 - 5 } BDNF & 5 5-HTT & Frequency & Median & Quartile & Statistics \\
\hline $\mathrm{A}^{+}$ & $\mathrm{S}^{+}$ & 97 & 11 & 9 & $\mathrm{H}=5.99$, \\
$\mathrm{GG}$ & $\mathrm{S}^{+}$ & 33 & 8 & 8 & $\mathrm{P}=0.015$ \\
$\mathrm{~A}^{+}$ & LL & 10 & 82 & 6 & \\
$\mathrm{GG}$ & LL & 2 & 20 & 12 & \\
\hline
\end{tabular}

5-HTT, serotonin transporter; BDNF, brain-derived neurotrophic factor.

Table VIII. Interaction between BDNF and NPSR1 polymorphisms and its affect on the depression score of asthmatic patients.

\begin{tabular}{lccccc}
\hline & & & \multicolumn{2}{c}{ Depression score } & \\
\cline { 5 - 5 } BDNF & NPSR1 & Frequency & Median & Quartile & Statistics \\
\hline $\mathrm{A}^{+}$ & $\mathrm{T}^{+}$ & 87 & 6 & 6 & $\mathrm{H}=4.22$, \\
$\mathrm{A}+$ & $\mathrm{AA}$ & 21 & 3 & 6 & $\mathrm{P}=0.04$ \\
$\mathrm{GG}$ & $\mathrm{T}^{+}$ & 30 & 4.5 & 7 & \\
$\mathrm{GG}$ & $\mathrm{AA}$ & 5 & 8 & 7 & \\
\hline
\end{tabular}

BDNF, brain-derived neurotrophic factor; NPSR1, neuropeptide S receptor 1.

gene was $89.36 \%$ (without anxiety), $93.88 \%$ (with anxiety), $90.84 \%$ (without depression) and $91.67 \%$ (with depression). LL only accounted for $10.64,6.12,9.16$ and $8.33 \%$, respectively. The frequency of the $\mathrm{A}^{+}$allele in the BDNF gene was $74.47 \%$ (without anxiety), 77.55\% (with anxiety), 76.34\% (without depression) and $66.67 \%$ (with depression); GG accounted for 25.53, 22.45, 23.66 and $33.33 \%$, respectively. The frequency of the $\mathrm{T}^{+}$allele in the NPSR1 gene was $82.98 \%$ (without anxiety), $79.59 \%$ (with anxiety), $81.68 \%$ (without depression), and $83.33 \%$ (with depression); and AA accounted for 17.02, 20.41, 18.32 and $16.67 \%$, respectively.

Correlation of 5-HTT, BDNF and NPSR1 gene polymorphisms with anxiety/depression scores. When the alleles were LL (5-HTT) and $\mathrm{A}^{+}$(BDNF), the anxiety score had the highest median value. Scheirer-Ray-Hare analysis demonstrated that the anxiety score was significantly affected by the interactions between 5-HTT $\left(\mathrm{LL}, \mathrm{S}^{+}\right)$and BDNF $\left(\mathrm{A}^{+}, \mathrm{GG}\right)(\mathrm{H}=5.99$, $\mathrm{P}=0.015)$, as shown in Table VII. In addition, BDNF gene polymorphisms were not detected in 1 patient. Therefore, there were data from 142 patients shown in Table VII. This suggests a synergistic effect of the interaction between 5-HTT and BDNF on the anxiety score. When the alleles were GG (BDNF) and AA (NPSR1), the depression score had the maximum median value. Scheirer-Ray-Hare analysis showed that the depression score was significantly affected by the interactions between BDNF $\left(\mathrm{A}^{+}, \mathrm{GG}\right)$ and NPSR1 $\left(\mathrm{AA}, \mathrm{T}^{+}\right)(\mathrm{H}=4.22, \mathrm{P}=0.04)$, as shown in Table VIII. The results suggest that the interaction between BDNF and NPSR1 had a synergistic effect on the depression score.

\section{Discussion}

Asthmatic patients are known to have a higher risk of developing mental disorders (25). The interactions between behavioral, neural, endocrine and immune processes have been studied in asthmatic patients and it has been noted that a major role is played by psychological factors in the development of asthma (26). The higher risk of anxiety and depression in asthmatic patients is also well documented (5,12,27-29). Furthermore, anxiety and depression are closely associated with poor asthma control and aggravated symptomatology $(2,3,30)$. Genetic polymorphisms may predispose asthmatic patients to anxiety or depression. In this study, we sought to examine the correlation between both anxiety and depression and the clinical characteristics of asthmatic patients, and we explored the association between NPSR1, BDNF and 5-HTT gene polymorphisms and anxiety and depression in these patients. We found no evidence of any association between age or education level and the occurrence of anxiety. However, depression was associated with a lower level of education, but not age. Both anxiety and depression negatively correlated with the ACT score.

Genetic factors are thought to influence the susceptibility of asthmatic patients to anxiety or depression. We noted that the interaction between 5-HTT (LL) and BDNF $\left(\mathrm{A}^{+}\right)$exerted a synergistic effect to increase the anxiety score in the asthmatic patients whereas the interaction between BDNF $\left(\mathrm{A}^{+}, \mathrm{GG}\right)$ and NPSR1 (AA, $\mathrm{T}^{+}$) exerted a synergistic effect to increase the depression score in asthmatic patients.

To explore a potential association between anxiety/depression and the demographic and clinical characteristics of the patients, we disaggregated the study subjects by age, gender, educational level and ACT scores. Consistent with a previous study (31), the incidence of asthma correlated with age and gender. However, significant differences in asthmatic patients with or without anxiety and with or without depression were not noted with respect to age or gender. The incidence of anxiety or depression was similar between males and females, as well as with respect to age. The results of our study differ from some earlier studies in this respect $(32,33)$. For example, in a study by Fernandes et al (33), the risk of anxiety was noted as being directly proportional to age, and inversely proportional to the socioeconomic level, particularly in women. Notably, we found that depression rather than anxiety was associated with a lower level of education. Consistent with the findings of previous studies $(2,3,5,7,10,34)$, both anxiety and depression were associated with poor asthma control, as evaluated by the ACT score in our study. Amelink et al (7) reported that patients with severe prednisone-dependent asthma were at a higher risk of emotional distress than those with severe non-prednisone dependent asthma, or those with mild to moderate asthma. Thus, co-existing anxiety and/or depression may be a major determinant of treatment outcomes in asthmatic patients. These findings underline the importance of screening asthmatic patients for anxiety and depression, as part of the routine management of these patients. Furthermore, adjunctive behavioral therapy or psychiatric intervention should be considered for these patients. 
Our study also assessed the role of genetic factors in contributing to the increased risk of anxiety or depression in asthmatic patients. We explored the association between SNPs of 5-HTT, BDNF and NPSR1 genes and anxiety or depression in asthmatic patients. Our results demonstrated an association between 5-HTT gene polymorphisms and anxiety in female asthmatic patients. To the best of our knowledge, this is the first report linking 5-HTT gene polymorphisms with anxiety in asthmatic patients. Caspi et al (35) reported an association between polymorphisms in the promoter region of the 5-HTT gene and the influence of stressful life events on depression. However, a meta-analysis of 14 independent studies (14) did not support this conclusion. This previous analysis showed that the 5-HTT polymorphism was not associated with an increased risk of depression in males alone, females alone or both males and females (14). $\mathrm{BDNF}$ is a neurotrophic factor which plays a critical role in maintaining the function of the neurons (21). It has also been reported to play a pivotal role in the pathogenesis of major depression and other mood disorders $(21,36)$. In addition to being highly expressed in the brain, it is also expressed in the lungs (37). Braun et al (38) suggested a link between BDNF and allergic bronchial asthma. Genetic variants of BDNF have been implicated in the causation of allergic asthma in various populations (19,22,39-41). However, whether polymorphisms of the BDNF gene predispose asthmatic patients to be affected by mood disorders has not yet been established. In the present study, gene polymorphisms in BDNF were not only associated with anxiety in female asthmatic patients, but were also linked with depression in the asthmatic population regardless of gender. These results suggest that BDNF genetic variants play an important role in the pathogenesis of anxiety and depression in asthmatic patients.

The NPS receptor signaling pathway is involved in the pathogenesis of asthma and allergies (42). It also regulates anxiety and arousal in rodents (43). Donner et al (22) suggested that the NPS and NPSR1 signaling pathway is involved in regulating human susceptibility to anxiety disorders. The NPSR 1 gene has been linked with asthma, high serum total IgE levels and other atopic diseases (44). By contrast, the present study showed that NPSR1 gene polymorphisms were not associated with either anxiety or depression in asthmatic patients.

Furthermore, we found that the $\mathrm{S}^{+}(5-\mathrm{HTT}), \mathrm{A}^{+}(\mathrm{BDNF})$ and $\mathrm{T}^{+}$(NPSR1) alleles had the highest frequency in the asthmatic patients regardless of anxiety or depression. More importantly, the risk and severity of anxiety or depression appeared to be influenced by the interaction between gene-gene polymorphisms. Asthmatic patients carrying both risk alleles 5-HTT (LL) and BDNF $\left(\mathrm{A}^{+}\right)$had enhanced anxiety scores, and those carrying risk alleles BDNF $\left(\mathrm{A}^{+}, \mathrm{GG}\right)$ and NPSR1 $\left(\mathrm{AA}, \mathrm{T}^{+}\right)$had increased depression scores. A previous study demonstrated that the NPSR1 polymorphism in AA carriers was linked to increased anxiety scores. However, the fear-potentiated startle is affected by the interaction between 5-HTT and NPSR1 polymorphisms (45). In our study, there was no evidence to suggest that the interaction between 5-HTT and NPSR1 polymorphisms plays a role in inducing anxiety or depression in asthmatic patients. Our findings suggest that anxiety and depression in asthmatic patients are influenced not only by polymorphisms of individual genes, but also by interactions between different gene polymorphisms.
It is necessary to acknowledge some limitations of our study. In the present study, the assessment of anxiety and depression was undertaken using a simple questionnaire, without conducting a structured interview. Another limitation is the cross-sectional study design, due to which the results may not be consistent over time. The third possible limitation is the existence of selection bias in the study, as all the patients were enrolled from a single hospital.

In conclusion, the present study demonstrates differences in the risk factors for anxiety and depression in asthmatic patients. Depression was negatively associated with the level of education. There was a correlation between both anxiety and depression and poor asthma control. The interaction between 5-HTT (LL) and BDNF $\left(\mathrm{A}^{+}\right)$appeared to increase the risk of anxiety, whereas the interaction between $\mathrm{BDNF}\left(\mathrm{A}^{+}, \mathrm{GG}\right)$ and NPSR1 (AA, $\mathrm{T}^{+}$) appeared to increase the risk of depression in asthmatic patients.

\section{Acknowledgements}

We would like to thank Dr Xiaojin Yu and his research team at the Southeast University School of Public Health for assistance with statistical analysis. We would like to thank Professor Ran Liu at the Southeast University School of Public Health for assistance in genetic testing.

\section{References}

1. Grainge C, Thomas PS, Mak JC, Benton MJ, Lim TK and Ko FW: Year in review 2015: Asthma and chronic obstructive pulmonary disease. Respirology 21: 765-775, 2016.

2. Valença AM, Falcão R, Freire RC, Nascimento I, Nascentes R, Zin WA and Nardi AE: The relationship between the severity of asthma and comorbidities with anxiety and depressive disorders. Rev Bras Psiquiatr 28: 206-208, 2006.

3. Di Marco F, Verga M, Santus P, Giovannelli F, Busatto P, Neri M, Girbino G, Bonini S and Centanni S: Close correlation between anxiety, depression, and asthma control. Respir Med 104: 22-28, 2010.

4. Thoren $\mathrm{C}$ and Petermann F: Reviewing asthma and anxiety. Respir Med 94: 409-415, 2000.

5. Coban $\mathrm{H}$ and Aydemir Y: The relationship between allergy and asthma control, quality of life, and emotional status in patients with asthma: a cross-sectional study. Allergy Asthma Clin Immunol 10: 67, 2014

6. Katon WJ, Richardson L, Lozano P and McCauley E: The relationship of asthma and anxiety disorders. Psychosom Med 66: 349-355, 2004.

7. Amelink M, Hashimoto S, Spinhoven P, Pasma HR, Sterk PJ, Bel EH and ten Brinke A: Anxiety, depression and personality traits in severe, prednisone-dependent asthma. Respir Med 108: 438-444, 2014.

8. Cheng Z, Dai LL, Li F, Liu Y, Kang Y, Chen HJ, Wang X, Zhang $\mathrm{H}$ and Ni R: Relationship between anxiety, depression and asthma control. Zhonghua Yi Xue Za Zhi 92: 2128-2130, 2012 (In Chinese).

9. Deshmukh VM, Toelle BG, Usherwood T, O'Grady B and Jenkins CR: The association of comorbid anxiety and depression with asthma-related quality of life and symptom perception in adults. Respirology 13: 695-702, 2008.

10. Kullowatz A, Kanniess F, Dahme B, Magnussen H and Ritz T: Association of depression and anxiety with health care use and quality of life in asthma patients. Respir Med 101: 638-644, 2007.

11. Letitre SL, de Groot EP, Draaisma E and Brand PL: Anxiety, depression and self-esteem in children with well-controlled asthma: case-control study. Arch Dis Child 99: 744-748, 2014.

12. Liu S, Wu R, Li L, Liu L, Li G, Zhang X, Guo Y, Wang Y, Zhang H, $\mathrm{Li} \mathrm{G}$ and $\mathrm{Li} \mathrm{H}$ : The prevalence of anxiety and depression in Chinese asthma patients. PLoS One 9: e103014, 2014. 
13. Alvarez GG and Fitzgerald JM: A systematic review of the psychological risk factors associated with near fatal asthma or fatal asthma. Respiration 74: 228-236, 2007.

14. Risch N, Herrell R, Lehner T, Liang KY, Eaves L, Hoh J, Griem A, Kovacs M, Ott J and Merikangas KR: Interaction between the serotonin transporter gene (5-HTTLPR), stressful life events, and risk of depression: a meta-analysis. JAMA 301: 2462-2471, 2009.

15. Mann JJ, Huang YY, Underwood MD, Kassir SA, Oppenheim S, Kelly TM, Dwork AJ and Arango V: A serotonin transporter gene promoter polymorphism (5-HTTLPR) and prefrontal cortical binding in major depression and suicide. Arch Gen Psychiatry 57: 729-738, 2000.

16. Smeraldi E, Zanardi R, Benedetti F, Di Bella D, Perez J and Catalano M: Polymorphism within the promoter of the serotonin transporter gene and antidepressant efficacy of fluvoxamine. Mol Psychiatry 3: 508-511, 1998.

17. Park MH, Chang KD, Hallmayer J, Howe ME, Kim E, Hong SC and Singh MK: Preliminary study of anxiety symptoms, family dysfunction, and the brain-derived neurotrophic factor (BDNF) Val66Met genotype in offspring of parents with bipolar disorder. J Psychiatr Res 61: 81-88, 2015.

18. Hashimoto K, Shimizu E and Iyo M: Critical role of brain-derived neurotrophic factor in mood disorders. Brain Res Brain Res Rev 45: 104-114, 2004.

19. Watanabe T, Fajt ML, Trudeau JB, Voraphani N, Hu H, Zhou X, Holguin F and Wenzel SE: Brain Derived Neurotrophic Factor (BDNF) Expression in Asthma. Association with Severity and Type-2 Inflammatory Processes. Am J Respir Cell Mol Biol: 844-852, 2015

20. Ozek E and Ekici B: Asthma and suicide: possible role of brain-derived neurotrophic factor. Med Hypotheses 77: 261-262, 2011.

21. Tsai SJ: Asthma, major depression and brain-derived neurotrophic factor. Med Hypotheses 65: 417-418, 2005.

22. Andiappan AK, Parate PN, Anantharaman R, Suri BK, Wang Y and Chew FT: Genetic variation in BDNF is associated with allergic asthma and allergic rhinitis in an ethnic Chinese population in Singapore. Cytokine 56: 218-223, 2011.

23. Donner J, Haapakoski R, Ezer S, Melén E, Pirkola S, Gratacòs M, Zucchelli M, Anedda F, Johansson LE, Söderhäll C, et al: Assessment of the neuropeptide $\mathrm{S}$ system in anxiety disorders. Biol Psychiatry 68: 474-483, 2010.

24. Asthma Workgroup CTS; Chinese Medical Association: Guideline Chinese expert consensus on bronchial asthma control Chin J Tuberc Respir Dis 31: 177-185, 2008 (In Chinese)

25. Feldman JM, Siddique MI, Morales E, Kaminski B, Lu SE and Lehrer PM: Psychiatric disorders and asthma outcomes among high-risk inner-city patients. Psychosom Med 67: 989-996, 2005.

26. Di Marco F, Santus P and Centanni S: Anxiety and depression in asthma. Curr Opin Pulm Med 17: 39-44, 2011

27. Adams RJ, Wilson DH, Taylor AW, Daly A, Tursan d'Espaignet E, Dal Grande E and Ruffin RE: Psychological factors and asthma quality of life: a population based study. Thorax 59: 930-935, 2004.

28. Alonso J, de Jonge P, Lim CC, Aguilar-Gaxiola S, Bruffaerts R, Caldas-de-Almeida JM, Liu Z, O'Neill S, Stein DJ, Viana MC, et al: Association between mental disorders and subsequent adult onset asthma. J Psychiatr Res 59: 179-188, 2014.

29. Scott KM, Von Korff M, Ormel J, Zhang MY, Bruffaerts R, Alonso J, Kessler RC, Tachimori H, Karam E, Levinson D, et al: Mental disorders among adults with asthma: results from the World Mental Health Survey. Gen Hosp Psychiatry 29: 123-133, 2007.

30. Leander M, Lampa E, Rask-Andersen A, Franklin K, Gislason T, Oudin A, Svanes C, Torén K and Janson C: Impact of anxiety and depression on respiratory symptoms. Respir Med 108: $1594-1600,2014$
31. de Marco R, Locatelli F, Sunyer J and Burney P: Differences in incidence of reported asthma related to age in men and women. A retrospective analysis of the data of the European Respiratory Health Survey. Am J Respir Crit Care Med 162: 68-74, 2000.

32. Sundberg R, Torén K, Franklin KA, Gislason T, Omenaas E, Svanes C and Janson C: Asthma in men and women: treatment adherence, anxiety, and quality of sleep. Respir Med 104: 337-344, 2010

33. Fernandes L, Fonseca J, Martins S, Delgado L, Pereira AC, Vaz M and Branco G: Association of anxiety with asthma: subjective and objective outcome measures. Psychosomatics 51: 39-46, 2010.

34. Trzcinska H, Zwierzchowska B, Kozlowski B, Derdowski S and Przybylski G: Analysis of the role of selected demographic and psychological variables (anxiety and depression) as risk factors of inadequate control of bronchial asthma. Ann Agric Environ Med 20: 504-508, 2013.

35. Caspi A, Sugden K, Moffitt TE, Taylor A, Craig IW, Harrington H, McClay J, Mill J, Martin J, Braithwaite A and Poulton R: Influence of life stress on depression: moderation by a polymorphism in the 5-HTT gene. Science 301: 386-389, 2003.

36. Castrén E, Võikar V and Rantamäki T: Role of neurotrophic factors in depression. Curr Opin Pharmacol 7: 18-21, 2007.

37. Lommatzsch M, Braun A, Mannsfeldt A, Botchkarev VA, Botchkareva NV, Paus R, Fischer A, Lewin GR and Renz H: Abundant production of brain-derived neurotrophic factor by adult visceral epithelia. Implications for paracrine and target-derived Neurotrophic functions. Am J Pathol 155: 1183-1193, 1999.

38. Braun A, Lommatzsch M, Mannsfeldt A, Neuhaus-Steinmetz U, Fischer A, Schnoy N, Lewin GR and Renz H: Cellular sources of enhanced brain-derived neurotrophic factor production in a mouse model of allergic inflammation. Am J Respir Cell Mol Biol 21: 537-546, 1999.

39. Jesenak M, Babusikova E, Evinova A, Banovcin P and Dobrota D: Val66Met polymorphism in the BDNF gene in children with bronchial asthma. Pediatr Pulmonol 50: 631-637, 2014.

40. Szczepankiewicz A, Breborowicz A, Sobkowiak P and Popiel A: Association of BDNF gene polymorphism with asthma in Polish children. World Allergy Organ J 3: 235-238, 2010.

41. Zeilinger S, Pinto LA, Nockher WA, Depner M, Klopp N, Illig T, von Mutius E, Renz H and Kabesch M: The effect of BDNF gene variants on asthma in German children. Allergy 64: 1790-1794, 2009.

42. Ilmarinen P, James A, Moilanen E, Pulkkinen V, Daham K, Saarelainen S, Laitinen T, Dahlen SE, Kere J, Dahlen B and Kankaanranta H: Enhanced expression of neuropeptide S (NPS) receptor in eosinophils from severe asthmatics and subjects with total IgE above 100IU/ml. Peptides 51: 100-109, 2014.

43. Xu YL, Gall CM, Jackson VR, Civelli O and Reinscheid RK: Distribution of neuropeptide $S$ receptor mRNA and neurochemical characteristics of neuropeptide S-expressing neurons in the rat brain. J Comp Neurol 500: 84-102, 2007.

44. Bernier V, Stocco R, Bogusky MJ, Joyce JG, Parachoniak C, Grenier K, Arget M, Mathieu MC, O'Neill GP, Slipetz D et al: Structure-function relationships in the neuropeptide $S$ receptor: molecular consequences of the asthma-associated mutation N107I. J Biol Chem 281: 24704-24712, 2006.

45. Glotzbach-Schoon E, Andreatta M, Reif A, Ewald H, Tröger C, Baumann C, Deckert J, Mühlberger A and Pauli P: Contextual fear conditioning in virtual reality is affected by 5HTTLPR and NPSR1 polymorphisms: effects on fear-potentiated startle. Front Behav Neurosci 7: 31, 2013 